\title{
Changing Scenario of Regional Anaesthesia Practice in Northeast India
}

Himjyoti Das ${ }^{1}$, Surajit Giri ${ }^{2}$ Langpoklakpam Chaoba Singh ${ }^{3}$

${ }^{1}$ Department of Anaesthesia \& Critical care, Nazareth Hospital, Shillong, Meghalaya.

2Department of Anaesthesia, Pragati Hospital \& Research Centre, Sivasagar, Assam.

${ }^{3}$ Department of Anaesthesia \& Critical care, RIMS, Imphal, Manipur.

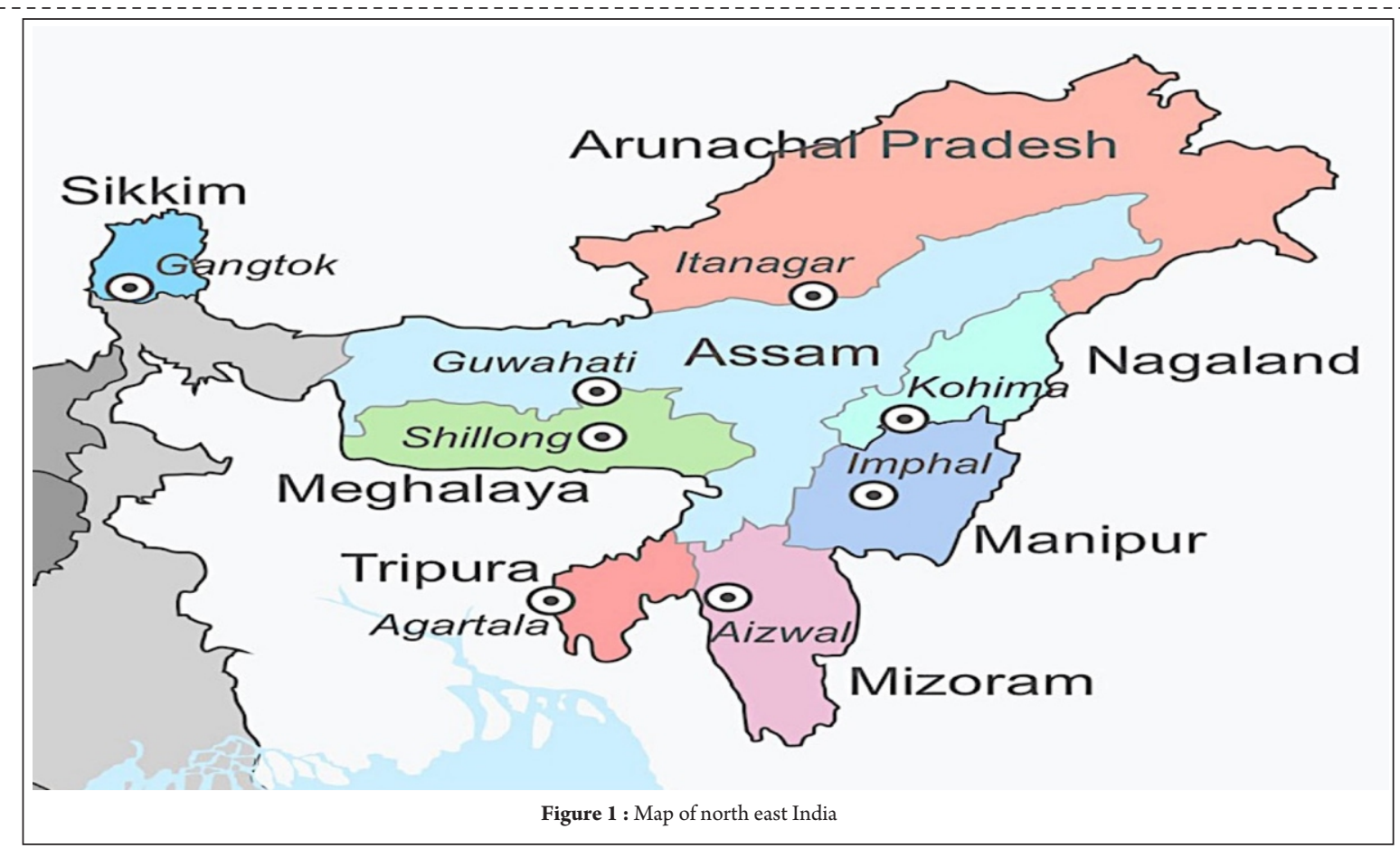

The North-East (NE) region of India comprises of eight states- Arunachal Pradesh, Assam, Manipur, Meghalaya, Mizoram, Nagaland, Sikkim and Tripura. (Fig 1)

The anaesthesia services in remote areas of this region are greatly restricted due to inadequate qualified manpower and infrastructure, as very few postgraduate and DNB (Diplomate National Board) seats are available each year across 4 out of 8 states through the NEET PG Test. (Fig $2 a \& 2 b$ )

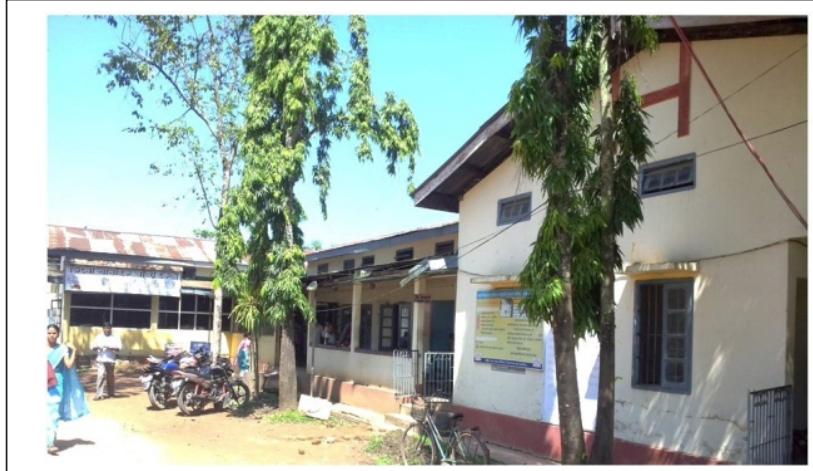

Figure 2a: A typical remote hospital with bare minimum facility in northeast India

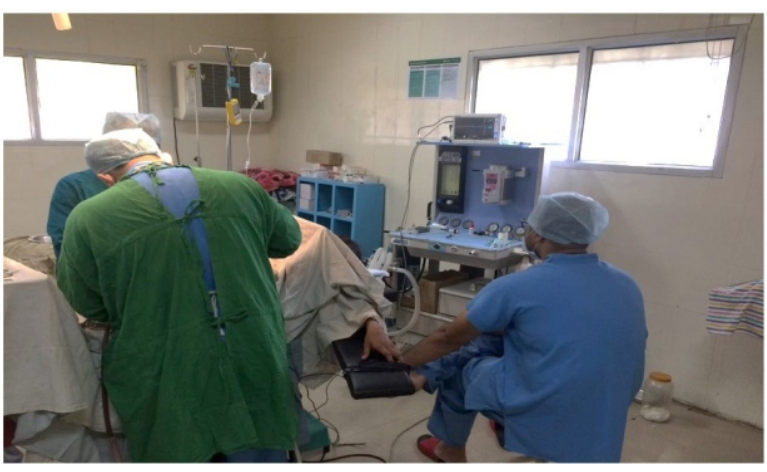

Figure 2b: An operation theatre in a remote area of northeast India Address of Correspondence: Dr. Surajit Giri, Pragati Hospital \& Research Centre, Sivasagar, Assam.

E-mail: drsurajitgiri@outlook.com

Submitted: 10 February 2021; Reviewed: 22 March 2021; Accepted: 15 April 2021; Published: 1 May 2021

DOI: 10.13107/ijra.2021.v02i02.039 | www.ijrajournal.com |

This is an Open Access article distributed under the terms of the Creative Commons Attribution Non-Commercial-Share Alike 4.0 License

(http://creativecommons.org/licenses/by-nc-sa/4.0) which allows others to remix, tweak, and build upon the work non-commercially as long as appropriate credit is given and the new creation are licensed under the identical terms. 
Regional Anaesthesia (RA) has several benefits in certain patients over general anaesthesia. It not only allows for better post-operative pain management and a comfortable post-operative patient, but also allows for safer surgeries in patients with comorbidities that carry potentially lifethreatening risks with general anaesthesia, especially in a resource limited areas.

The practice of RA took a backseat in the recent past due to lack of proper training in RA and the absence of a structured curriculum during PG training. However, during the last decade, we have witnessed a paradigm shift in RA and PNB (Peripheral nerve block) anaesthesia with continued support from Academy of Regional Anaesthesia (AORA) \& Indian Society of Anesthesiologists (ISA).

For better understanding of the changing scenario of regional anaesthesia practice in this region over years, we may divide the time-in into two phases, late $20^{\text {th }}$ century and the $21^{\text {st }}$ century.

\section{0-2000}

Assam Medical College (AMC), Dibrugarh is one of the pioneering institutes in post-graduate (PG) training in Anaesthesia in North-East India, which started its postgraduate training program in 1971. Prof. Ajit Kumar Deka (Fig 3), former Head of the Department of Anaesthesia \& Critical Care, Guwahati Medical College (GMC) narrates"Since mid 1960s when the first fully independent Anaesthesiology department was established in AMC, spinal anaesthesia (SA) was used with Lignocaine heavy for practically all surgeries below the diaphragm including those of upper abdomen. Cholecystectomy \& Gastrojejunostomy (GJ) were done under SA. In between late $60^{\mathrm{s}}$ and early $70^{\mathrm{s}}$ some surgeries were done with hypobaric technique using Nupercaine. In early $1970^{\mathrm{s}}$ intravenous regional anaesthesia (IVRA) was used for upper and lower limb surgeries. Most of the anaesthesiologists were fond of this technique during that time. SA for upper abdominal surgeries continued till around 1980 and then gradually abandoned due to frequent association with patient discomfort and need for GA

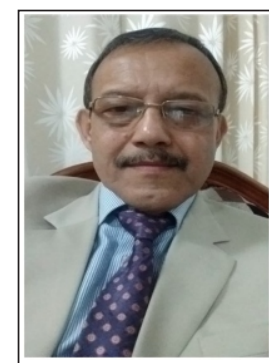

Prof. Ajit Kumar Deka

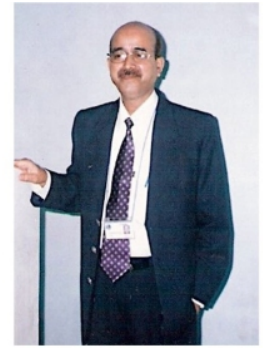

Prof. Rajib Kumar Bhattacharyya Figure 3

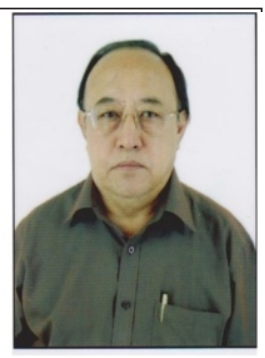

Prof. H.S.Singh supplementation, moreover by that time better and safer drugs for GA were made available in the region.

Going along with the world trend, SA was almost abandoned in the medical colleges from mid $80^{\mathrm{s}}$ to 1990 for the fear of delayed neurological complications. During this period single shot epidural anaesthesia (EA) slowly came into practice. However, throughout this period till 1990, RA was not used for caesarean section in the region except for in some missionary hospitals. By this time anaesthesiologists were well trained in EA/SA and continuously used them in clinical practice. However nerve blocks were not practiced routinely during that period."

Prof. Rajib Kumar Bhattacharyya (Fig. 3), former Head of the Department of Anaesthesia \& Critical Care, AMC, Dibrugarh, describes his experience "During the early $80^{\mathrm{s}}$ regional blocks were mainly restricted to the anatomical landmark techniques. The first clinical study on paravertebral block for post-operative analgesia was done in the year 1986. By the middle of the $90^{\mathrm{s}}$, use of epidural anaesthesia was slowly introduced in practice, mostly with single shot technique. From 1980 till the early $2000^{\text {s }}$, the use of SA for caesarean delivery was restricted to full stomach patients."

Dr.Amal Kumar Laha, former Associate Professor, Department of Anaesthesia Silchar Medical college, Assam, comments - "In 1980s SA was used for most obstetric surgeries. Few upper limb surgeries were done under landmark guided brachial plexus block in 1990",

It is obvious from the above narrations from our respected teachers that till the beginning of this century, RA meant only SA, though few anaesthesiologists practised landmarks guided PNB in this region.

Same stories were regarding practice of regional anaesthesia were narrated from Imphal and Tripura.

Prof. Subhas Ranjan Das, present Prof. and HOD, Department of Anaesthesia, Agartala Government Medical College, Tripura narrates -

“Till 1990, RA wasn't practised in Tripura except SA. From 1990 onwards, landmark guided axillary and supraclavicular nerve blocks \& IVRA were practised sporadically in few district hospitals."

Regional Institute of Medical Sciences (RIMS) at Imphal (Manipur) is another institute of repute for medical education in the NE region. According to Prof. H.S Singh (Fig. 3), retired Prof. and Head of Anaesthesia at RIMS, "most of the upper limb surgeries performed in the 80 s were with TIVA technique and few hand surgeries were performed under landmark guided wrist and axillary block, though most lower limb surgeries were performed under Spinal or single shot epidural anaesthesia. With the addition of PNS (Peripheral nerve stimulator) machine, more 


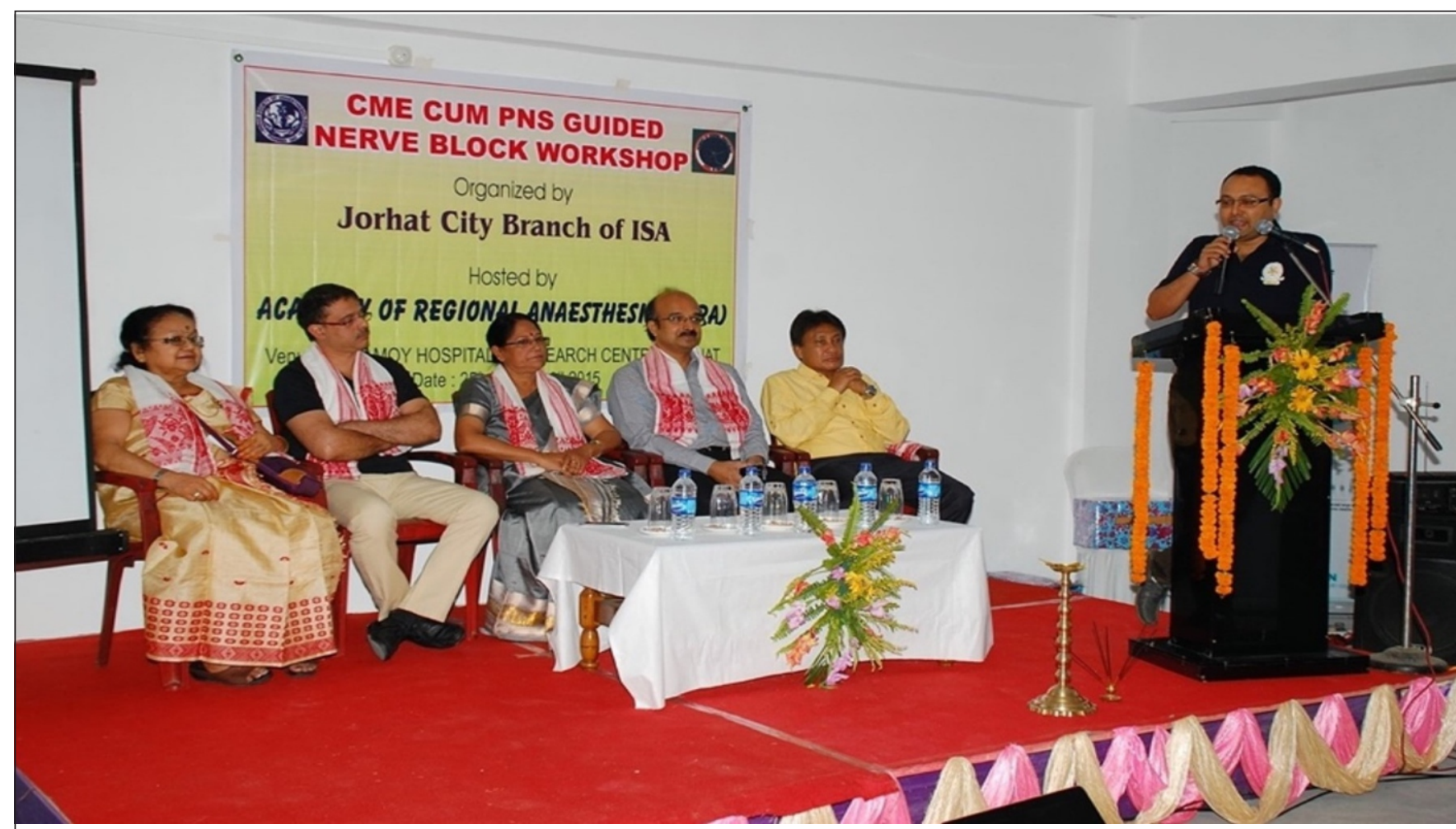

Figure 4: CME at Jorhat, Assam

surgeries were performed under PNB (Peripheral nerve block) from early 2000 and subsequently a few hospitals in Imphal started to use ultrasound for PNB since then".

\section{0-2010}

The brachial plexus blocks evolved slowly during this period, and though post-graduate training was initiated, upper limb blocks were seldom practiced. Devoid of gadgets, the anesthesiologists mostly relied on facial clicks or needlenerve contact (paresthesia) and a large amount of local anesthetics for a successful block. For a successful needle tip placement, our teachers relied more on the 'POP' technique and the needle movement with arterial pulsation. Less commonly those blocks were successful needing intraoperative supplementation of large dose of sedatives or even conversion to general anesthesia.

Gradually, a few determined and enthusiastic RA anesthesiologists started to get themselves trained in different institutes in India and slowly started to practice and make RA more and more popular in this region.

\section{0-2020}

Remarkable changes were noticed regarding the practice of RA in NE during this period. More CME (Continued Medical Education) and workshops were conducted in different areas and many more anesthesiologists came forward to learn and start practicing RA.
On $25^{\text {th }}$ and $26^{\text {th }}$ April 2015 for the first time, a CME cum LIVE workshop of RA was organized at Jorhat (Fig. 4), Assam. Around 100 practising anesthesiologists from Assam and NE attended the workshop. Dr J. Balavenkatasubramanian and Dr Sandeep Diwan from AORA demonstrated PNS guided upper limb and lower limb blocks. That was an incitement to our practising anesthesiologists of NE. A one to one interaction with the experts motivated the delegates to perform simple nerve block in routine clinical practice.

With PNB by PNS gaining popularity, discouragement followed from various quarters. Therefore, it was decided to address the surgeons and public on concerns regarding safety and relevance of RA in modern day surgical procedures, through a live video demonstration from the operation theatre to general public in a Dibrugarh hospital premise. (Fig. 5a, 5b) Accordingly, a screen was placed in the hospital waiting area where public could visualize and understand various RA techniques. It was the first experiment of such kind, and it reached many people, raising awareness about use of RA in safe surgeries among public and society. Media also witnessed and published about the event in various platforms of media which helped the cause to reach a wider section of society. (Fig. 5c)

Steadily the NE anaesthesiologists transformed from PNS to USG guided nerve block. On $5^{\text {th }}$ April 2017, for the first-time USG guided LIVE nerve block workshop (Fig. 6a \& 6b) was 


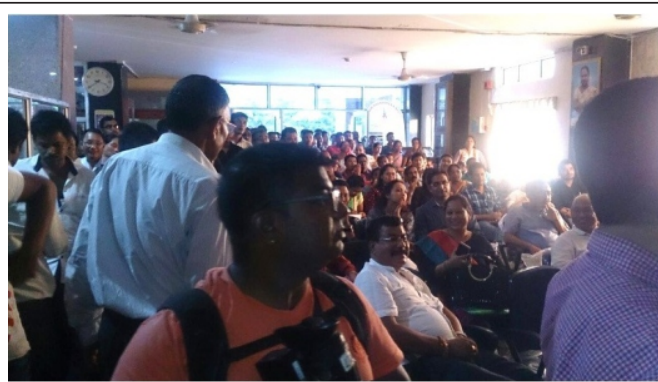

Figure 5a: General public enjoying PNB straight from the operation theatre

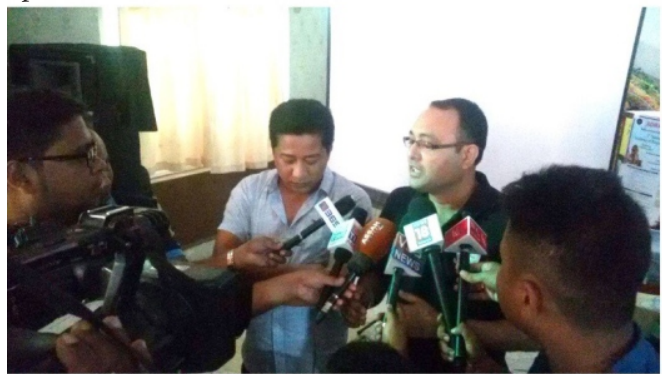

Figure 5c: Media briefing during the workshop at Dibrugarh

organised at Pratiksha hospital in Guwahati with faculties from AORA demonstrating various operating room live blocks to enthusiastic anaesthesiologists from across northeastern states.

ISA Manipur branch organised an ultrasound guided PNB CME and workshop at RIMS (Fig. 5d) Imphal on $25^{\text {th }} \& 26^{\text {th }}$ March 2017 with faculties from AIIMS, New Delhi participating. This was the first of its kind CME cum workshop in Manipur.

AORA continued to help carry forward the cause of

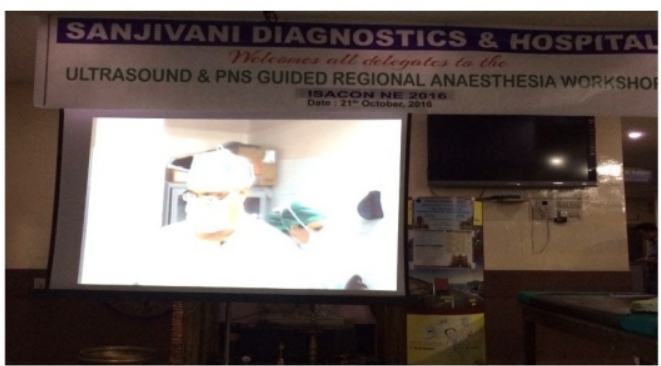

Figure 5b: Dr Sandeep Diwan demonstrating PNB to Anaesthesiologists \& to general public

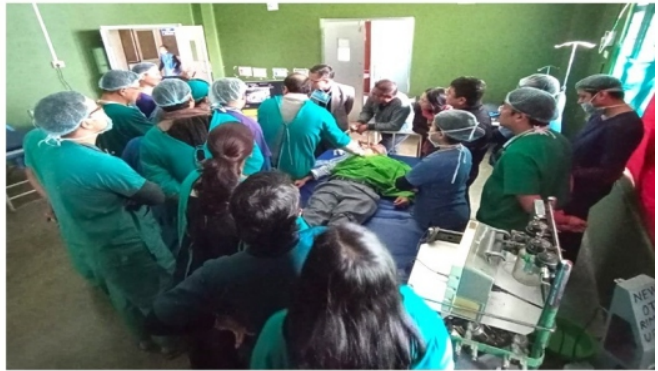

Figure 5d: USG guide PNB workshop in Imphal, March 2017

promoting RA practice in NE region with its faculties conducting a workshop on $19^{\text {th }}$ January 2018 at Tezpur. (Fig. $7 \mathrm{a} \& 7 \mathrm{~b})$

From the year 2018, onwards under the aegis of AORA and ISA, several hands-on workshops cum CME were conducted at different parts of the entire region namely, Aizawl in Mizoram (9a), Imphal in Manipur (8a, 8b) and Dibrugarh in Assam $(8 \mathrm{c}, 8 \mathrm{~d})$

Before the beginning of the current pandemic, a CME cum hands on workshop was conducted at Shillong in February

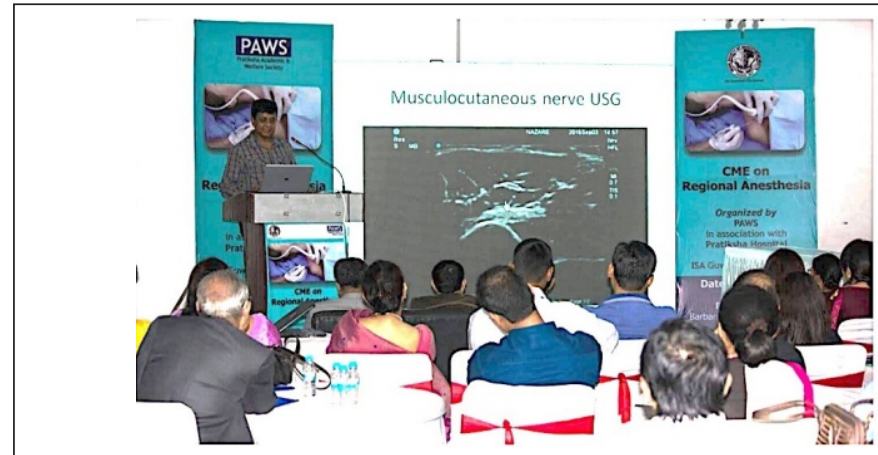

Figure 6a: USG guided PNB workshop in Guwahati

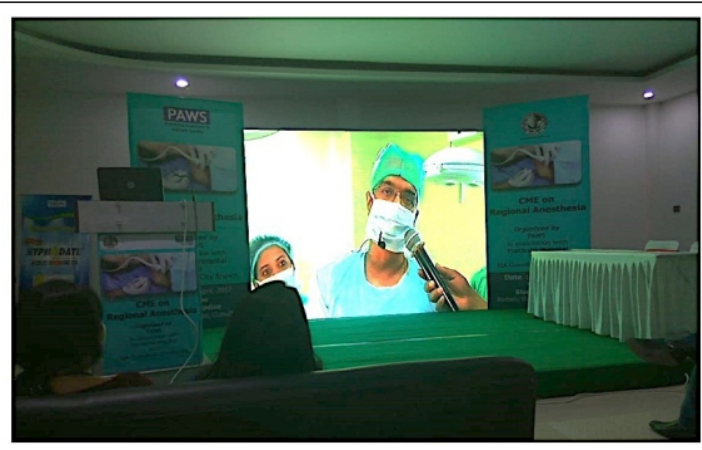

Figure 6b: CME cum Live workshop at Guwahati
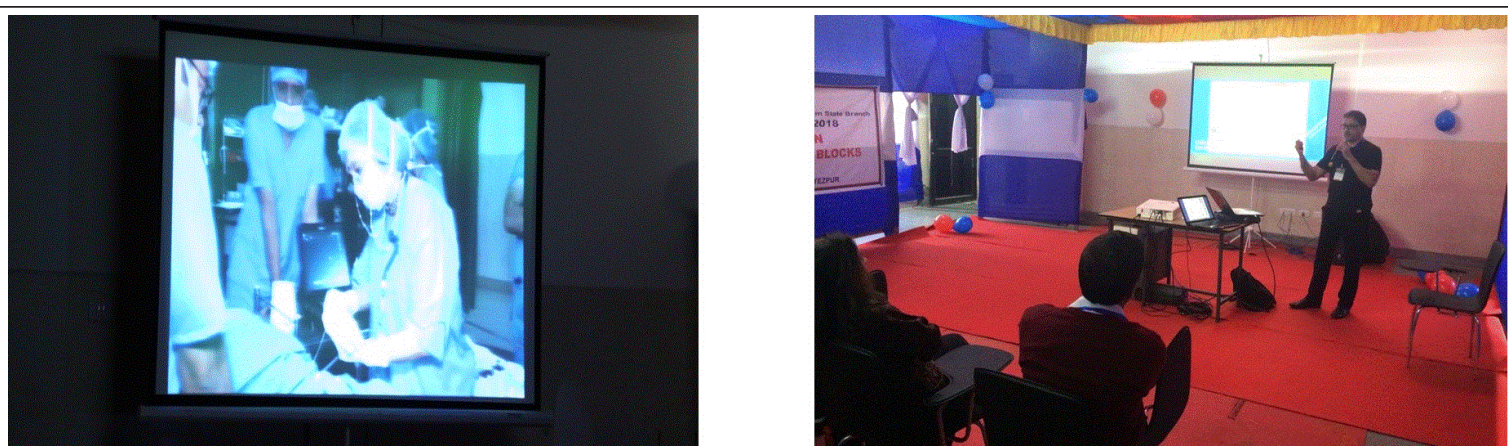

Figure 7a and 7b: Dr Vrushali Ponde and Dr S. Diwan at Tezpur Medical college, Assam 

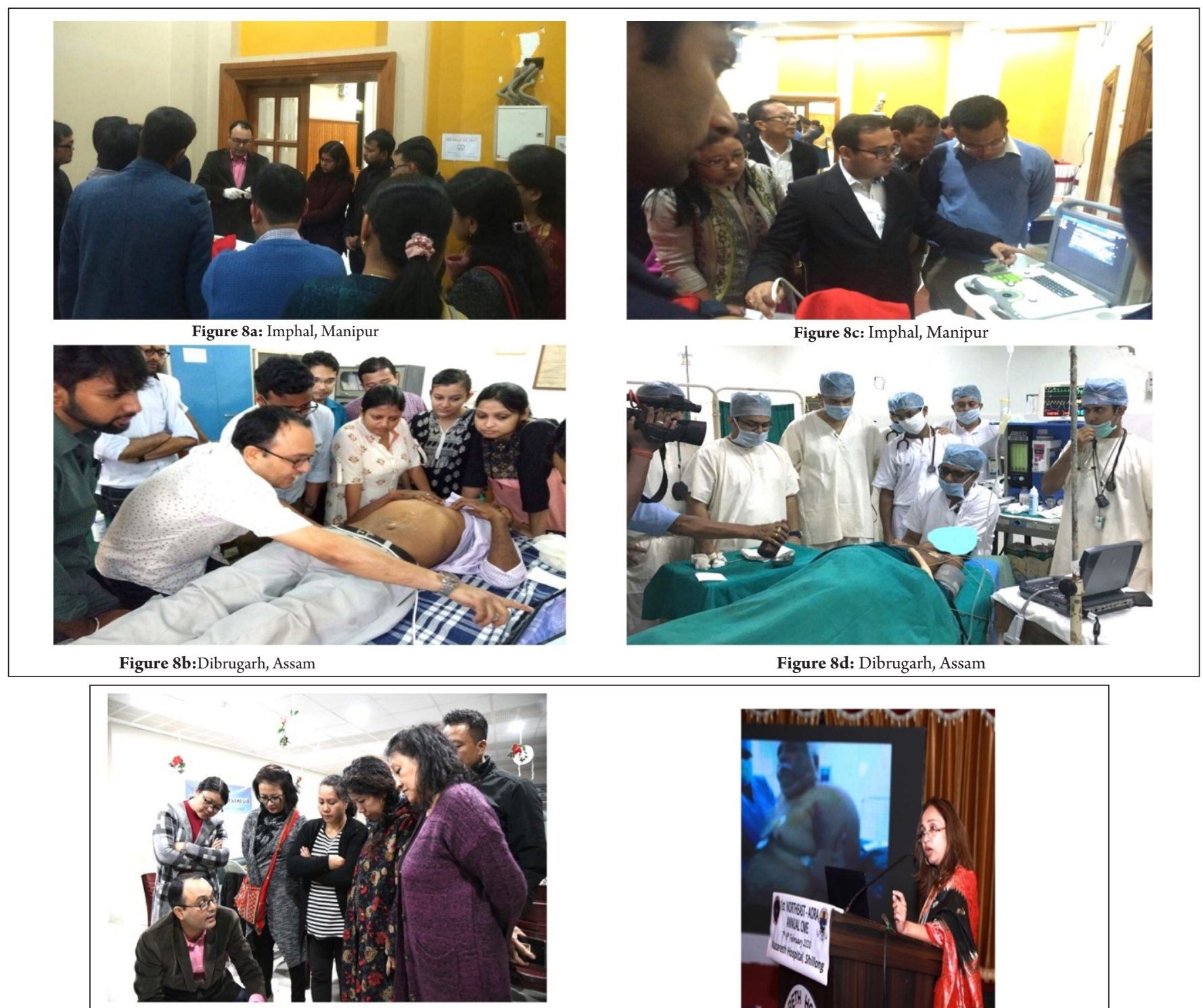

Figure 9a: Aizawl, Mizoram on $15^{\text {th }}$ December 2018

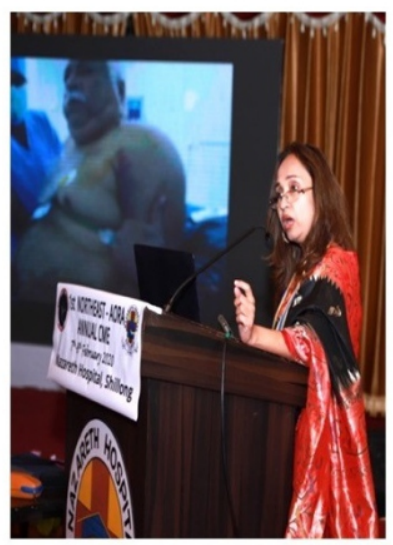

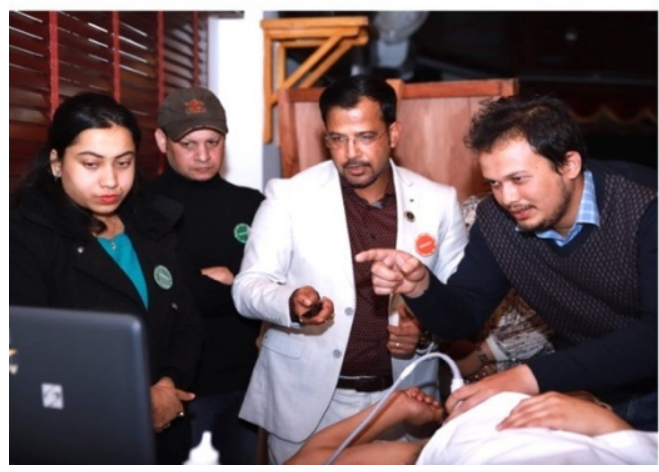

Figure 9c: CME cum workshop on regional anaesthesia at Shillong, February 2020
Figure 9b: CME cum workshop on regional anaesthesia at Shillong, February 2020

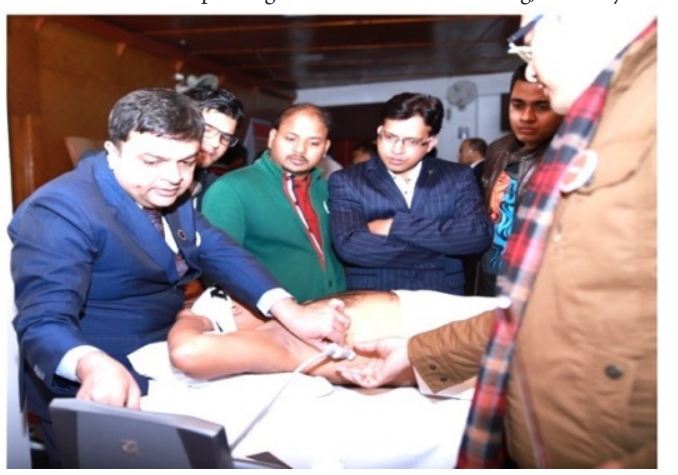

Figure 9d: CME cum workshop on regional anaesthesia at Shillong, February 2020

2020 (Fig. 9b, 9c, 9d) with around 50 delegates participating from across NE states along with delegates from one neighbouring county, 8 AORA national and 10 regional faculties conducted the workshop.

To understand the impact and outcomes of regional anaesthesia workshop and CME'S a survey was conducted through Google form during the month of May 2021. Unpretentious questionnaires were sent to139 actively practising anesthesiologists of NE. The questionnaire included questions related to changing trend of regional anesthesia practice 

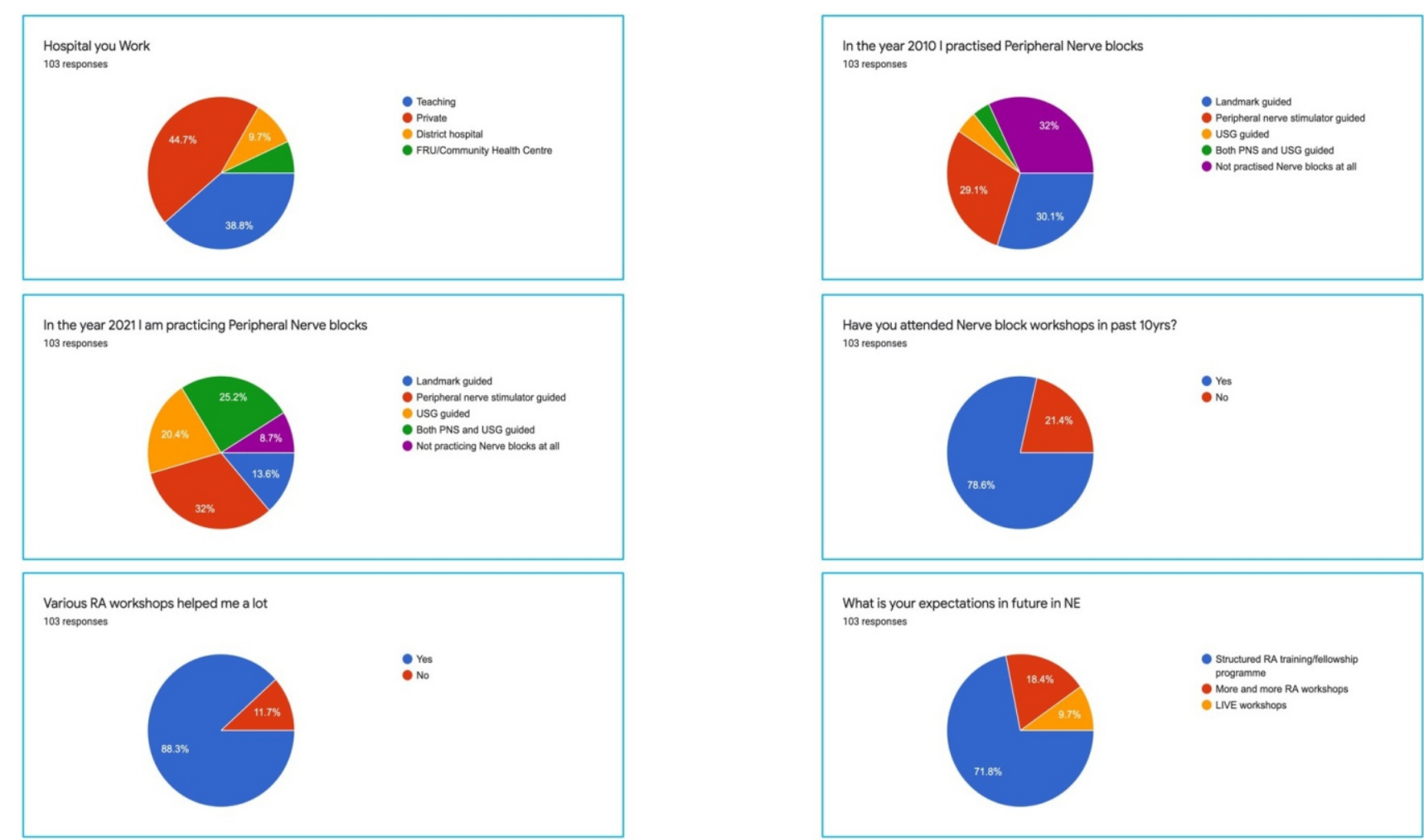

Figure 10: Survey of anesthesiologists from all states of North-East

amongst anesthesiologist of north east such as

1) Did you/do you practice peripheral nerve block in the year 2000/2021?

2) What technique of PNB have you used/do you use in the year 2000/2021?

Anesthesiologists from all states of NE participated in the survey. Of the 139 anesthesiologists from community health center, teaching hospitals and private practising anesthesiologist, 103 participated in the survey. A break up revealed, $44.75 \%$ were from private hospital, 38.8\% were from teaching hospitals and rest were from district and community health centres from different parts of NE. (Fig. 10)

Comparison between the year 2010 and 2021 revealed, 32\% did not practice nerve block in 2010 versus $8.7 \%$ is not practicing in 2021. A surge of more than $23 \%$ was noted in accepting and implementing regional anaesthesia in a 11year duration.

The practice of landmark guided nerve blocks in 2010 (30.1\%) changed to neurostimulation guided block (13.16\%) in 2021 , while $4.9 \%$ were administrating USG nerve blocks in 2010 as against $20.4 \%$ in 2021 . Only $3.9 \%$ were practising both PNS and USG for PNB in the year 2010 against $25.2 \%$ in 2021 , The survey further divulged that $78.6 \%$ attended various regional anaesthesia workshops in different parts of NE, $88.3 \%$ believed that various RA workshops helped them a lot in learning RA/PNB and $71.8 \%$ feels that this region lacks structured RA training.

Our survey clearly reveals the impact of conducting regional anaesthesia workshops and CME's. Significant changing trends of RA in NE during the last two decades are observed, with more anesthesiologists slowly (30\% vs $13.6 \%$ during a 11 year period) switching from landmarks to PNS to USG to both PNS and USG in 2021. AORA RA workshops in association with ISA have paved the path for the upliftment of RA practices in NE. It was a paradigm shift amongst practising anesthesiologists of $\mathrm{NE}$, and the willingness to change played a pivotal role.

With continued presence of AORA in the NE region for various workshops and CMEs, headed by the likes of Dr J. Balavenkatasubramanian, Dr Sandeep Diwan, and Dr Vrushali Ponde, the region has witnessed a major change in the practices of RA from Landmark technique in $80^{\circ}$ to PNS and subsequently the use of US guided nerve blocks which is increasing the safety to patients and helping to minimize their pain in perioperative period.

To continue the journey of promoting safe and effective RA practices in NE India a structured module of training in RA for PG and young anesthesiologists to further enhance the practical knowledge of regional anaesthesia, is proposed. Perhaps a visit to the anatomy halls, a cadaveric workshop would add to the existing knowledge of regional nerve blocks.

As number of practising anesthesiologist are very few in 
remote locations of NE and it is difficult for them to attend zonal and national conferences regularly, small focussed CME and workshops with one to one interaction with experts are definitely going to help them in acquiring new skills and broadening their knowledge of regional anaesthesia incoming days.

Declaration of patient consent: The authors certify that they have obtained all appropriate patient consent forms. In the form, the patient has given his consent for his images and other clinical information to be reported in the Journal. The patient understands that his name and initials will not be published, and due efforts will be made to conceal his identity, but anonymity cannot be guaranteed.

Acknowledgment: We are highly indebted to AORA and ISA for lending continuous support for the cause of sharing knowledge for best practice of RA in NE India.

We acknowledge the support of Sonosite India, B-Braun and Neon India for their continuous support in this journey.

We also acknowledge the support of faculty members of different medical colleges, private institutes and office bearer of different city and state branch for holding regular CMEs and workshops on RA in this region.

Conflict of interest: Nil Source of support: None

How to cite this article: Das H, Giri S, Singh LC | Changing Scenario of Regional Anaesthesia Practice in Northeast India International Journal of Regional Anaesthesia | July-December 2021; 2(2): 117-123. 